\title{
LAND USE AND LAND COVER CLASSIFICATION OF SENTINEL 2-A: ST PETERSBURG CASE STUDY
}

\author{
M. Cavur ${ }^{1}$, H.S. Duzgun², S. Kemec ${ }^{3}$, D. C. Demirkan ${ }^{4}$ \\ ${ }^{1}$ Management Information System, Kadir Has University, Istanbul, Turkey - mahmut.cavur@khas.edu.tr \\ ${ }^{2}$ Mining Engineering Department, Colorado School of Mines, Denver, USA - duzgun@mines.edu \\ ${ }^{3}$ Department of Urban and Planning, Van Yuzuncu Yil University, Van, Turkey - serkankemec@yyu.edu.tr \\ ${ }^{4}$ Mining Engineering Department, Colorado School of Mines, Denver, USA - dogacagdasdemirkan@gmail.com
}

\section{Commission I, WG I/10}

KEY WORDS: LULC, Land Use Land Cover, SVM, Sentinel 2A Analysis

\begin{abstract}
:
Land use and land cover (LULC) maps in many areas have been used by companies, government offices, municipalities, and ministries. Accurate classification for LULC using remotely sensed data requires State of Art classification methods. The SNAP free software and ArcGIS Desktop were used for analysis and report. In this study, the optical Sentinel-2 images were used. In order to analyze the data, an object-oriented method was applied: Supported Vector Machines (SVM). An accuracy assessment is also applied to the classified results based on the ground truth points or known reference pixels. The overall classification accuracy of $83,64 \%$ with the kappa value of 0.802 was achieved using SVM. The study indicated that of SVM algorithms, the proposed framework on Sentinel-2 imagery results is satisfactory for LULC maps.
\end{abstract}

\section{INTRODUCTION}

Land Use Land Cover Maps are extensively used in many different organizations for various purposes. Since the usage and purpose vary, the importance of data itself and the analysis of data are really important for critical and accurate decisions. LULC maps are created by classification of images which are aerial photographs or satellite images in general. Urban is dynamic in nature, and up-to-date data is required for timelymanner information and analysis (Cavur et al, 2015).

Mapping and monitoring of land cover have been widely recognized as an important scientific goal since created information could be used to support environmental and atmospheric models, decision-making procedures etc. Currently, most of this information is collected by means of statistics, surveys, and mapping or digitizing from aerial imagery. However, the statistical data is usually course at spatial and temporal scales for large urban environments (Cavur et al, 2015). Recently, real-time information is important for critical decision and therefore, the data and the analysis methodology are critical to providing up-to-date results. In the data side, ESA has been providing Sentinel images for various purposes. Sentinel 2 data can meet the analysis requirements with its properties. Spatial resolution is one of the most important properties of satellite sensors that varies $\mathrm{cm}$ to $\mathrm{km}$ (Demirkan, Duzgun, 2017). Spectral resolution is another important property of a satellite sensor. Since Sentinel 2 data is multispectral, can be concluded successfully for LULC classes (Demirkan, Duzgun, 2017).

LANDSAT, SPOT, IRS, IKONOS, MODIS, NOAA-AVHRR and RADARSAT are several satellites that can be used for EO purpose. The spatial and spectral resolution for that mission can vary and meet various requirements. Since the Sentinel 2 data spatial resolution is between $10-30 \mathrm{~m}$, it can meet several important requirements for LULC (Manakos, Levander, 2014).
There are many fields of study and research fields that utilize remotely sensed data. Landsat, SPOT, IKANOS, and MODIS have spectral and/or spatial characteristics and mission objectives similar to those of Sentinel-2. The recent research related to the Sentinel-2 includes comparing Landsat-8 classification accuracies with Sentinel-2, sub-pixel feature detection evaluation between Landsat-8, Sentinel-2. Likewise, SOPT-5 failed to detect some large landscape features due to spectral limitations. On the other hand, undetected objects were successfully detected by Sentinel-2 (Radoux et al, 2016) (Demirkan, Duzgun, 2017).

Image classification for EO data has gained popularity among many researchers. There are many classification methods (George et al, 2012). Image classification is the process of assigning pixels/objects of the image to the predefined land use land cover classes. It is a complicated and time-consuming procedure and the result is affected by different factors such as classification method, nature, and the type of urban structure etc. In order to get a convincing result to be used by urban planners, combining the different classification approaches would be necessary.

The main objective of this study is to use Sentinel-2A satellite images and prove that the Sentinel 2 images are usable for classification with a good and reasonable accuracy for LULC.

\section{METHODOLOGY AND DATA}

\subsection{Data}

The urban area covered in this study is part of St Petersburg, where Sentinel 2A satellite image is used. It There are many classification approaches which applied to the Sentinel satellite images. For instance, in a fusion approach for Sentinels data is introduced (Kaplan et al, 2018). It is proved that the objectoriented approach better than the pixel-based approach for LULC classification (Maglione et al, 2013 and Kaplan et al, 
2018), In this study, the SVM classification approach is applied on Sentinel 2 data with a unique methodology. The SVM's performance is dependent on the selection of the appropriate kernel type and (Petropoulos et al, 2007). In this study a radial basis function kernel is selected as it is found to be more suitable for LULC applications (Petropoulos et al, 2007) has the 13 bands resolution images among the satellite.

The main objective of Sentinel 2 satellite are providing data for risk management, land use and land cover mapping, change detection, natural hazards, water management. Sentinel-2 gives global coverage every five days. It is equipped with a multispectral imager (MSI) with 13 bands (Drusch et al, 2012).

Figure 1 shows the selected site from St Petersburg, which covers a central business district, densely built up with road features and river.

At first, the product of Sentinel 2-A was opened in SNAP. It was resampled in 10 meters in all bands because of further applications. Then, the image was saved as in ENVI format and further steps were applied in ENVI.

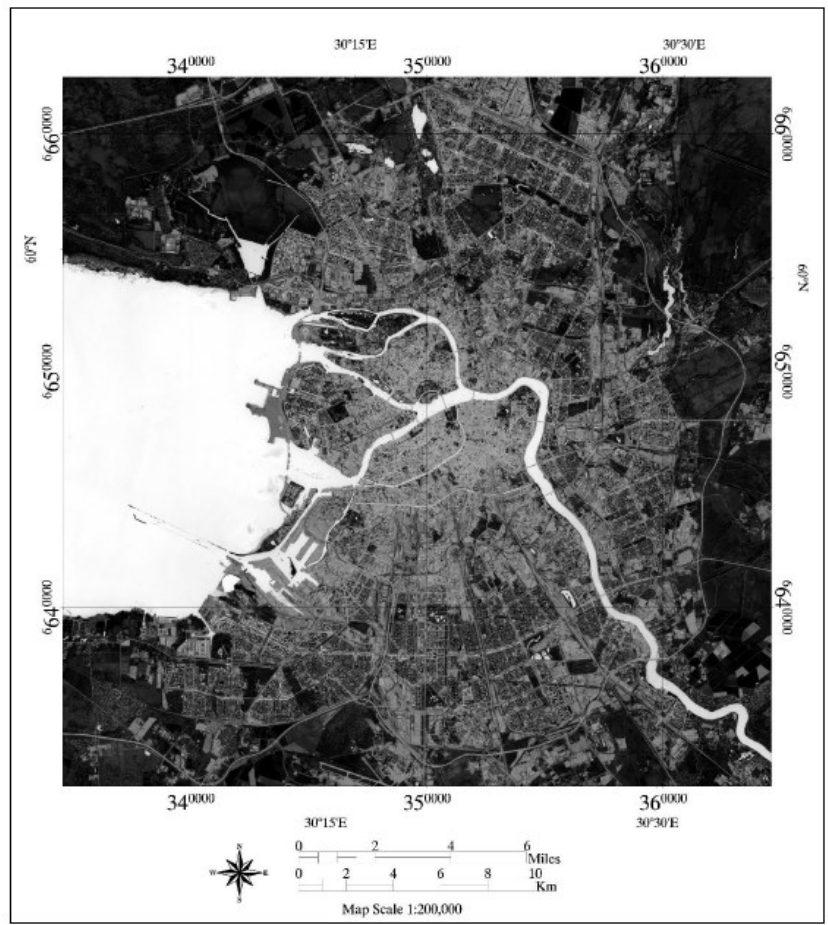

Figure 1. Sentinel 2 image for the study area in St. Petersburg.
Deutschland, INRA, and UCL and named Sentinels Application Platform.

The first classification level of this study consisted of four main classes which are water, vegetation, bare land and build up. For classification of the first level, there were three pre-steps. The first step was creating normalized difference vegetation index (NDVI), the second was creating normalized difference water index (NDWI) and the third was masking the image with these indices. After these steps, SVM was applied for classification. Second level classification and class combination are also done by ENVI. In second level classification, all classes had their own masked image. For example, in water class, only the water containing areas had a normal pixel value and the others were zero, which means that all pixels appeared black during the visualization of the area. Those raw data were created before first level classification. Again, for second level classification, SVM was used and LULC maps were created.

Last part of the study was accuracy assessment. In order to verify that this study is legitimate, accuracies and kappa coefficients of each test were calculated.

Details of the study steps are given in Figure 2. The numbers near each class represent the CORINE LULC hierarchy code.

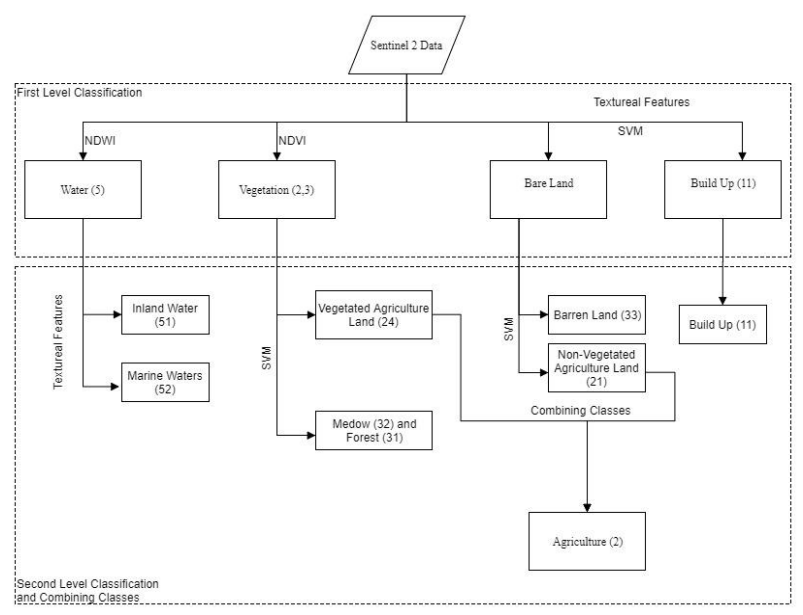

Figure 2. Flowchart of the applied classification methodology.

Vegetation can be extracted from NDVI (El-Gammal et al, 2014). NDVI formula is given in the following equation. Figure 3 indicates the NDVI of the interested region.

$\mathrm{NDVI}=[(\mathrm{NI}-\mathrm{Red}) /(\mathrm{NI}+\mathrm{Red})]$

\subsection{Methodology}

The research methodology followed in this study has five steps, which are data collection, preprocessing, first level classification, second level classification and combining classes and accuracy assessment which is shown in Figure 1.

In data collection phase, ESA Sentinel Online website was used (https://scihub.copernicus.eu/dhus/). Drawing region of interest and making a search is described in the same website. All the data are available free of charge.

Preprocessing has been done by the application called SNAP which was developed for ESA by CS in partnership with Brockmann Consult, CS-Romania, Telespazio Vega 


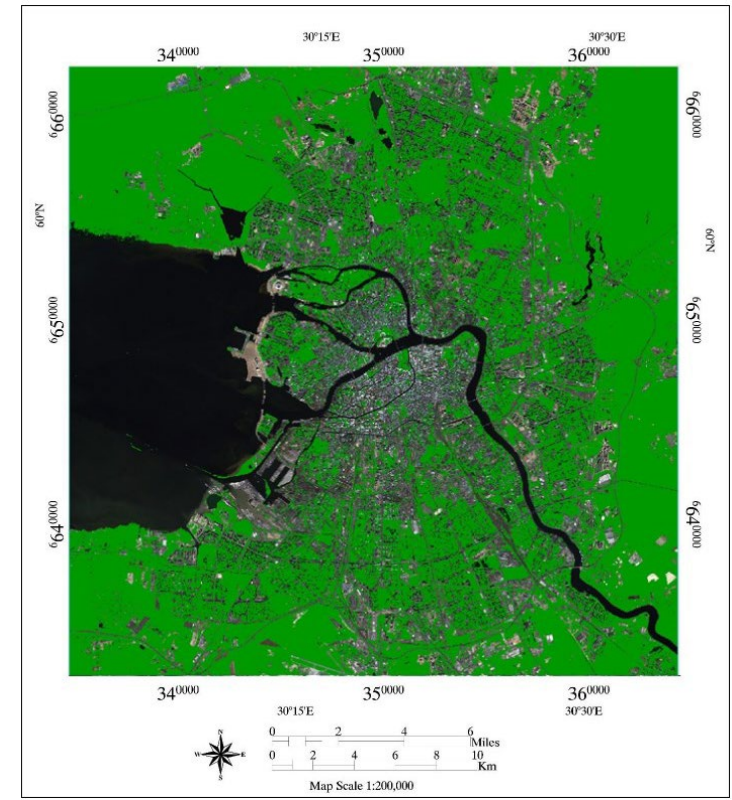

Figure 3. NDVI ROI before the mask.

Then some thresholding should be done for extracting water. NDWI formula is given in the following equation (Qiao et al, 2012). Figure 4 indicates the NDWI of the interested region. $\mathrm{NDVI}=[($ Green-NI $) /($ Green $+\mathrm{NI})]$

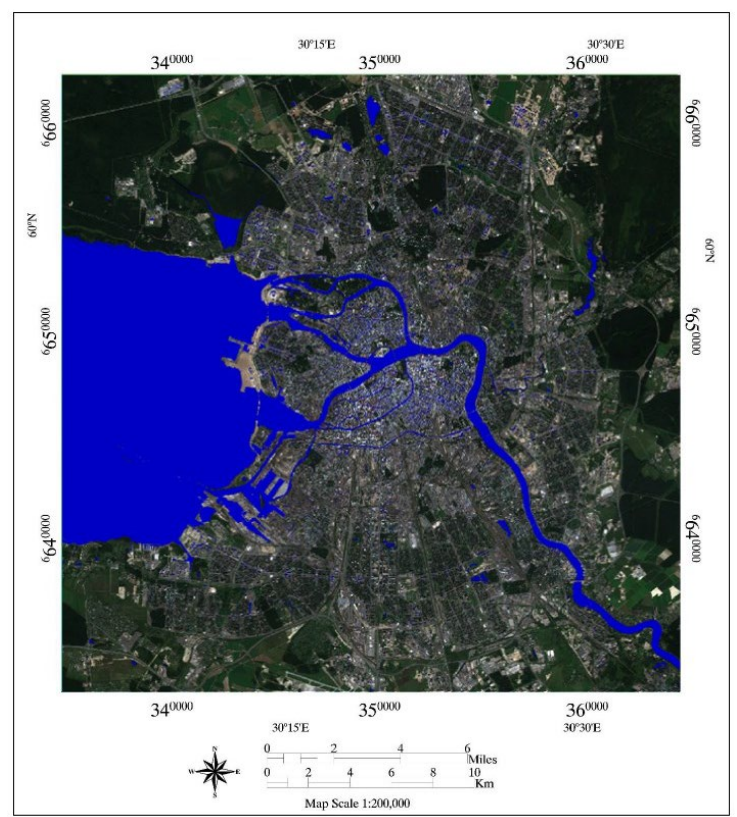

Figure 4. NDWI ROI before the mask.

\section{RESULT AND DISCUSSION}

In this study, each step in each level increases the accuracies of the classification. Using NDVI and NDWI was very helpful.

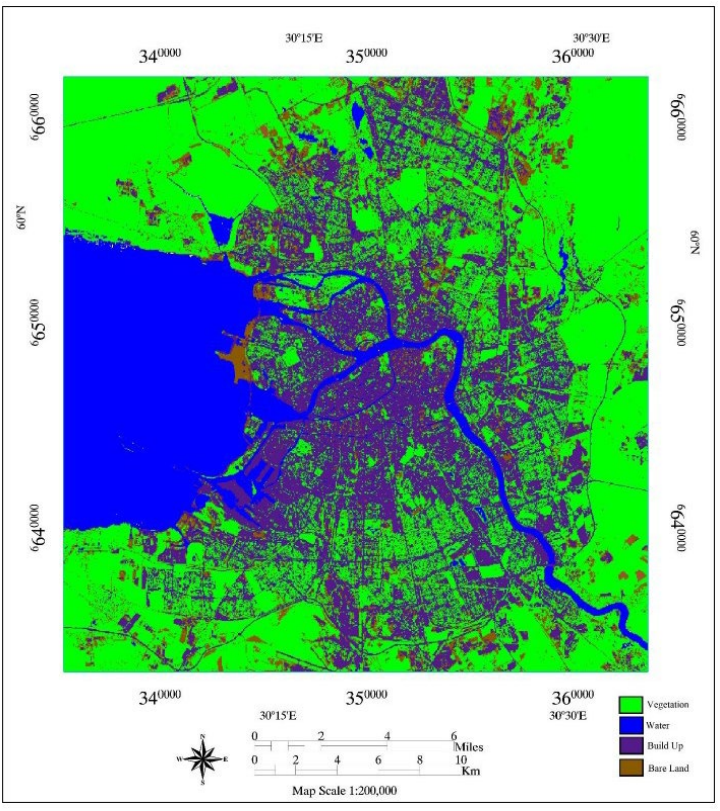

Figure 5. First-Level Classification results.

In this level classes of the classification data divided into subcategories and some categories merged together shown in the flowchart of the framework. For example, water is divided into inland water and marine water. Vegetation is divided into forest and vegetated agriculture land. Bare land is divided into barren land and non-vegetated agriculture land. Then vegetated and non-vegetated agriculture lands are combined.

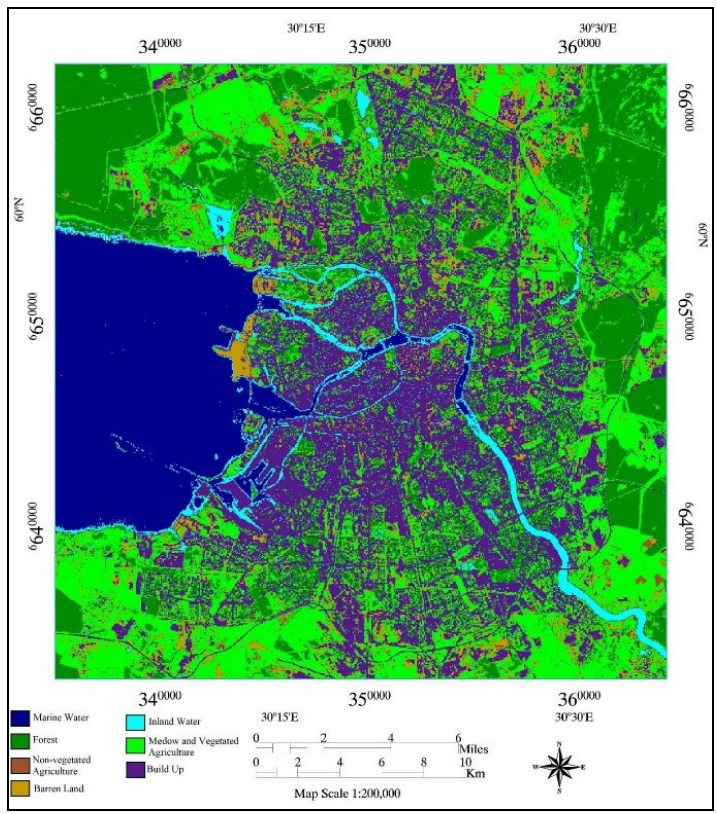

Figure 6. Second-Level Classification results. 


\begin{tabular}{|c|c|c|c|c|c|c|c|c|c|}
\hline & 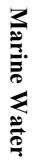 & 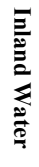 & $\begin{array}{l}-1 \\
\frac{0}{2} \\
\stackrel{2}{2}\end{array}$ & 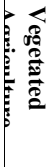 & 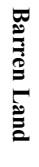 & 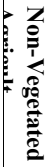 & 畕. & $\stackrel{n}{\Xi}$ & 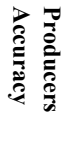 \\
\hline $\begin{array}{l}\text { Marine } \\
\text { Water }\end{array}$ & 20 & 0 & 0 & 0 & 0 & 0 & 0 & 20 & $100 \%$ \\
\hline $\begin{array}{l}\text { Marine } \\
\text { Water }\end{array}$ & 3 & 17 & 0 & 0 & 0 & 0 & 0 & 20 & $85 \%$ \\
\hline Forest & 0 & 0 & 20 & 0 & 0 & 0 & 0 & 20 & $100 \%$ \\
\hline $\begin{array}{l}\text { Vegetataed } \\
\text { Agriculture }\end{array}$ & 0 & 0 & 1 & 38 & 1 & 0 & 0 & 40 & $95 \%$ \\
\hline $\begin{array}{l}\text { Barren } \\
\text { Land }\end{array}$ & 0 & 0 & 0 & 2 & 36 & 2 & 10 & 50 & $72 \%$ \\
\hline $\begin{array}{l}\text { NonVeg. } \\
\text { Agriculture }\end{array}$ & 0 & 0 & 1 & 2 & 5 & 9 & 3 & 20 & $45 \%$ \\
\hline Build-up & 0 & 0 & 0 & 0 & 6 & 0 & 44 & 50 & \\
\hline Sum & 23 & 17 & 22 & 42 & 48 & 11 & 57 & 220 & Ov Acc \\
\hline $\begin{array}{l}\text { Users } \\
\text { Accuracy }\end{array}$ & 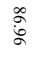 & :ें & 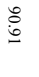 & $\begin{array}{l}\stackrel{8}{\infty} \\
+\infty\end{array}$ & $\begin{array}{l}\text { पे } \\
\ddot{8}\end{array}$ & $\stackrel{\infty}{\infty}$ & ज्ञ & $\begin{array}{l}\gtrsim \\
\gtrless \\
\text { b }\end{array}$ & $\begin{array}{l}\infty \\
\stackrel{\infty}{q} \\
\stackrel{2}{2}\end{array}$ \\
\hline
\end{tabular}

Table 1. Accuracy assessment

The overall accuracy and Kappa coefficient is found to be 83.64 and 0.802 , respectively for Sn Petersburg. Accuracy measures given in Table I indicate that even for a complex scene considered as the study area, water, forest and vegetated have high accuracy values. Although the other classes' accuracy values are less than water, forest and vegetation, they can be considered to be satisfactory for urban planning purposes.

\section{CONCLUSION}

The main objective of this study was to create a LULC map and to test the capabilities of the newly launched Sentinel-2 sensor for EO.

Two steps of the framework were developed for similar data types to extract information for LULC. The methodology and framework with selected approach (SVM) were given reliable result for urban planning. The accuracy and Kappa statistics results which are 83.64 and 0.802 respectively are satisfactory for urban planning.

Consequently, it can be said that the methodology worked successfully for creating LULC maps with Sentinel-2 data. Its success is proven with the case study accuracy results and Kappa coefficients.

\section{ACKNOWLEDGMENT}

These case studies aim to provide a LULC classification output for the SEN4RUS project using Landsat 8 data and Sentinel 2A Sn Petersburg data to bridge the gap between EO scientists and urban planners. The authors thank the European Commission for funding the SEN4RUS project (ERA.Net-RUS-Plus). Also thanks to SEN4RUS Team for their valuable support for this project. la Orden, M. González-Audicanac, 2015: Object and Pixelbased Analysis for Mapping Crops and their AgroEnvironmental Associated Measures Using QuikBird Imagery, Computer, and Electronics in Agriculture 68, 2009, pp.207-215.

Cavur, M., S. Kemec, L. Nabdel, H.D. Duzgun, 2017: An evaluation of land use land cover (LULC) classification for urban applications with Quickbird and WorldView2 data, Urban Remote Sensing Event (JURSE), 2015 Joint, vol., no., pp.1,4, March 30 2015-April 12015.

Demirkan, D.C. and H.S. Duzgun, 2017: Land Use And Land Cover Classification Of Sentinel 2-A Images, Thesis,

Drusch, M., Del Bello, U., Carlier, S., Colin, O., Fernandez, V., Gascon, F., ... Bargellini, P., 2012: Sentinel-2: ESA's Optical High-Resolution Mission for GMES Operational Services. Remote Sensing of Environment, 120, 25-36. https://doi.org/10.1016/j.rse.2011.11.026

El-Gammal, M., Ali, R. R., \& Abaou Samra R.M., 2014: NDVI Threshold Classification for Detecting Vegetation Cover in Damietta Governorate, Egypt. Journal of American Science, 10(8), 108-114. https://doi.org/10.1111/1440-1681.12062

George P. Petropoulos, Chariton Kalaitzidis, Krishna Prasad Vadrevu, 2012: Support Vector Machines and Object-based Classification for Obtaining Land-Use/Cover Cartography from Hyperion Hyper spectral Imagery, Computers and Geosciences 41, 2012, pp.99-107.

Kaplan, Gordana, and Ugur Avdan. 2018: Sentinel-1 and Sentinel-2 Data Fusion for Wetlands Mapping: Balikdami, Turkey, International Archives of the Photogrammetry, Remote Sensing and Spatial Information Sciences - ISPRS Archives 42.3 (2018): 729-734.

Maglione, P., P. C., Vallario, A., 2013: Using Worldview-2 Satellite Imagery To Support Geoscience Studies On Phlegraean Area. American Journal of Geosciences 3 (1): 1-12, 2013.

Manakos I. and S. Lavender, 2014: Remote sensing in support of the geo-information in Europe. Remote Sensing and Digital Image Processing (Vol. 18). https://doi.org/10.1007/978-94007-7969-3 1

Petropoulos, G.P., Knorr1, W., Scholze1, M. Boschetti, L. Karantounias, G., 2007: Combining ASTER Multispectral Imagery Analysis and Support Vector Machines for Rapid and Cost-Effective Post-Fire Assessment: A Case Study from the Greek Wildland Fires of 2007. Nat. Hazards Earth Syst. Sci. 10, pp.305-317.

Qiao, C., Luo, J., Sheng, Y., Shen, Z., Zhu, Z., \& Ming, D., 2012: An Adaptive Water Extraction Method from Remote Sensing Image Based on NDWI. Journal of the Indian Society of Remote Sensing, 40(3), 421-433. https://doi.org/10.1007/s12524-011-0162-7

Radoux, J., G. Chomé, D.C. Jacques, F. Waldner, N. Bellemans, N. Matton, ... P. 2016: Defourny, Sentinel-2's potential for subpixel landscape feature detection. Remote Sensing, 8(6), https://doi.org/10.3390/rs8060488

\section{REFERENCES}

Castillejo-Gonzalez, I.L., F. López - Granados, A. GarcíaFerrer, J.M. Peña-Barragán, M. Jurado-Expósito, M. Sánchezde 